\title{
Rarity of invasiveness in right-sided infective endocarditis
}

\author{
Syed T. Hussain, MD, ${ }^{a}$ Nabin K. Shrestha, MD, ${ }^{b}$ James Witten, BA, ${ }^{c}$ Steven M. Gordon, MD, \\ Penny L. Houghtaling, MS, ${ }^{\mathrm{d}}$ Jens Tingleff, MD, ${ }^{\mathrm{e}}$ José L. Navia, MD, ${ }^{\mathrm{a}}$ Eugene H. Blackstone, MD, ${ }^{\mathrm{a}, \mathrm{d}}$ and \\ Gösta B. Pettersson, MD, $\mathrm{PhD}^{\mathrm{a}}$
}

\section{ABSTRACT}

Objective: The rarity of invasiveness of right-sided infective endocarditis (IE) compared with left-sided has not been well recognized and evaluated. Thus, we compared invasiveness of right- versus left-sided IE in surgically treated patients.

Patients and Methods: From January 2002 to January 2015, 1292 patients underwent surgery for active IE, 138 right-sided and 1224 left-sided. Among patients with right-sided IE, 131 had tricuspid and 7 pulmonary valve IE; 12\% had prosthetic valve endocarditis. Endocarditis-related invasiveness was based on echocardiographic and operative findings.

Results: Invasive disease was rare on the right side, occurring in 1 patient $(0.72 \%$; $95 \%$ confidence interval $0.02 \%-4.0 \%$ ); rather, it was limited to valve cusps/leaflets or was superficial. In contrast, IE was invasive in 408 of 633 patients with aortic valve (AV) IE (65\%), 113 of 369 with mitral valve (MV) IE (31\%), and 148 of 222 with AV and MV IE (67\%). Staphylococcus aureus was a more predominant organism in right-sided than left-sided IE (right 40\%, AV 19\%, MV $29 \%$ ), yet invasion was observed almost exclusively on the left side of the heart, which was more common and more severe with AV than MV IE and more common with prosthetic valve endocarditis than native valve IE.

Conclusions: Rarity of right-sided invasion even when caused by $S$ aureus suggests that invasion and development of cavities/"abscesses" in patients with IE may be driven more by chamber pressure than organism, along with other reported host-microbial interactions. The lesser invasiveness of MV compared with AV IE suggests a similar mechanism: decompression of MV annulus invasion site(s) toward the left atrium. (J Thorac Cardiovasc Surg 2018;155:54-61)

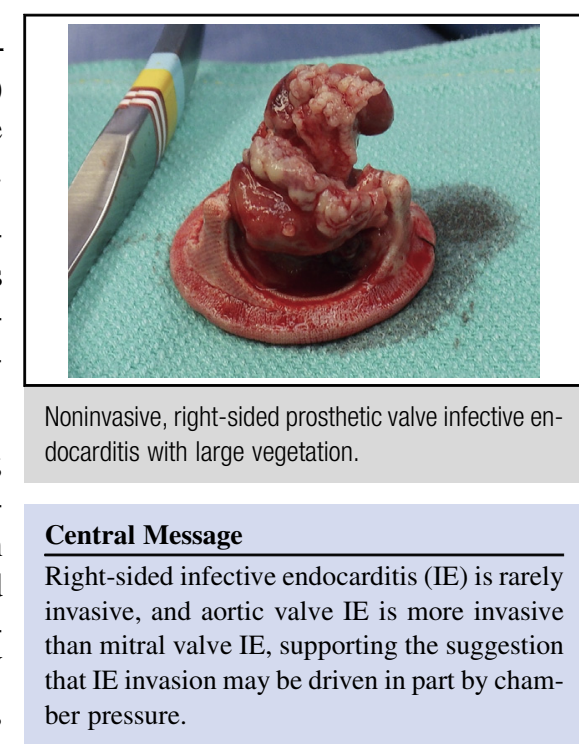

\section{Perspective}

The rarity of right-sided invasion, even when caused by Staphylococcus aureus, leads to the suggestion that invasive infective endocarditis may be driven more by chamber pressure than organism, along with other host-microbial interactions. Lesser invasiveness of mitral valve than aortic valve infective endocarditis suggests a similar mechanism: decompression of mitral annulus invasion site(s) toward the left atrium.

See Editorial Commentary page 62 .
From the ${ }^{\mathrm{a}}$ Department of Thoracic and Cardiovascular Surgery, Heart and Vascular Institute, ${ }^{\mathrm{b}}$ Department of Infectious Disease, Medicine Institute, ${ }^{\mathrm{c}}$ Lerner College of Medicine, and ${ }^{\mathrm{d}}$ Department of Quantitative Health Sciences, Research Institute, Cleveland Clinic, Cleveland, Ohio; and ${ }^{\mathrm{e}}$ Emergency Department, Hvidovre University Hospital, Copenhagen, Denmark.

This study was funded in part by the Gus P. Karos Registry Fund, the Kenneth Gee and Paula Shaw, PhD, Chair in Heart Research, the Peter and Elizabeth C. Tower and Family Endowed Chair in Cardiothoracic Research, James and Sharon Kennedy, the Slosburg Family Charitable Trust, Stephen and Saundra Spencer, and Martin Nielsen.

Read at The American Association for Thoracic Surgery Mitral Conclave, New York, New York, April 23-24, 2015.

Received for publication Dec 6, 2016; revisions received June 20, 2017; accepted for publication July 9, 2017; available ahead of print Sept 23, 2017.

Address for reprints: Gösta B. Pettersson, MD, PhD, Department of Thoracic and Cardiovascular Surgery, Cleveland Clinic, 9500 Euclid Ave/Desk J4-1, Cleveland, OH 44195 (E-mail: petterg@ccf.org).

$0022-5223 / \$ 36.00$

Copyright (c) 2017 by The American Association for Thoracic Surgery

http://dx.doi.org/10.1016/j.jtcvs.2017.07.068
Right-sided infective endocarditis (IE) is uncommon, accounting for only $5 \%$ to $10 \%$ of cases of $\mathrm{IE}^{1-3}$ with the vast majority $(90 \%)$ involving the tricuspid valve. ${ }^{2}$ Right- and left-sided IE behave as 2 distinct entities, both clinically and experimentally. ${ }^{4-7}$ As such, treatment has been approached differently, with most cases of tricuspid valve IE treated medically. ${ }^{1-3,8,9}$ Our clinical observation has been that in surgically treated right-sided IE, there is

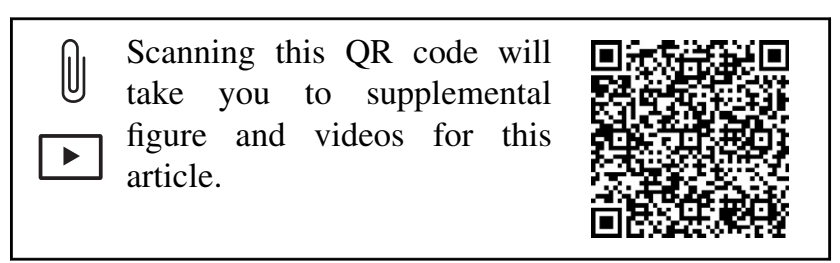




\section{Abbreviations and Acronyms \\ IE = infective endocarditis \\ $\mathrm{NVE}=$ native valve endocarditis \\ $\mathrm{PVE}=$ prosthetic valve endocarditis}

seldom invasive disease, a finding that has not been well recognized and evaluated in the literature or fully explained. In contrast, we previously reported that aortic valve IE is often locally invasive, more so than mitral valve IE. ${ }^{10}$ This difference in invasiveness may influence the clinical course and subsequent development of complications and may be important for informed clinical management.

Thus, we have reviewed all patients with active IE to formally compare invasiveness of right- and left-sided IE. To accomplish this, the spectrum of intraoperative IE pathologic features was categorized and pathology stageinvasive versus noninvasive-correlated with organism and IE context (affected valve and native valve endocarditis $[\mathrm{NVE}]$ vs prosthetic valve endocarditis [PVE]).

\section{PATIENTS AND METHODS \\ Patients}

From January 1, 2002, to January 1, 2015, 1564 consecutive patients underwent surgery for IE at Cleveland Clinic. Infectious disease and cardiac surgery registries were interrogated, medical records reviewed, and patients' IE classified with the use of modified Duke criteria. ${ }^{11}$ Active IE was defined by surgical findings, histopathologic evidence of active infection, or positive cultures from operative specimens. ${ }^{10,12}$ Cases not meeting criteria for active IE were excluded and coded as remote/healed IE (272 cases), leaving a study population of 1292 active IE cases. All active cases met Duke criteria for IE. Of these, 138 (68 isolated and 70 with concomitant left-sided involvement; Figures 1 and 2, Table 1) were right-sided IE and 1224 left-sided (Figure 3). Of the 138 patients with active right-sided IE, 131 had tricuspid valve IE and 7 pulmonary valve IE. Of these, 63 had isolated tricuspid valve (PVE 11\%) and 5 isolated pulmonary valve IE (PVE 60\%) without concomitant left-sided involvement. Seventeen $(12 \%)$ of all right-sided IE patients had PVE.
All patients were managed by an endocarditis team that included cardiology, infectious disease, and cardiac surgery expertise. The patients underwent evaluation and imaging of the brain, lungs, and spine when appropriate and clinically indicated before surgery. An effective antimicrobial regimen was managed by the infectious disease member of the team.

To provide complete context, in addition to these surgical cases, we identified from our infectious disease registry 347 patients with IE who were treated nonsurgically from July 2007 to January 2015. Of these, 51 had right-sided IE (33 isolated and 18 with concomitant left-sided involvement). In the absence of operative observations, invasiveness of IE in these 51 patients could be assessed only on echocardiographic images.

The Cleveland Clinic Institutional Review Board approved (no. 07-043, date January 30, 2007) the use of data extracted from all registries and medical records for use in research, with patient consent waived.

\section{IE Characteristics}

IE etiology was identified by review of microbiologic laboratory results and infectious disease serology. All operative reports, pre- and intraoperative echocardiograms (available in all patients), and surgical pathology findings were reviewed. IE-specific findings were coded and stored in a Research Electronic Data Capture (ie, REDCap) database, as previously described. $^{12}$

Invasive IE. IE was coded as noninvasive if pathology was confined to the cusps and leaflets and invasive if the infectious process extended beyond the cusps or leaflets into the annulus and surrounding structures. Stage of IE invasion was coded as (1) cellulitis: preabscess cellulitis, invasion without collections of pus or micro abscesses; (2) abscess: macroscopic collection of pus; (3) abscess cavity: cavity with debris and clots suggesting active IE; and (4) pseudoaneurysm: endothelialized cavity without pus. ${ }^{12}$ "Cellulitis/preabscess cellulitis" was considered a stage of invasion because it requires debridement and possible reconstruction, similar to the stage of invasion with pus collection or cavity/pseudoaneurysm, and would be missed only if the surgeon failed to recognize it. ${ }^{12}$ Definitive diagnosis of invasive disease was based on operative notes, echocardiography, or both. In the vast majority of cases, indisputable evidence of invasion was clearly noted and described in the operative notes and resulted in debridement and reconstruction. Occasional operative notes lacked sufficient details, but if echocardiography demonstrated indisputable evidence of invasion, these cases were classified as invasive. Independent verification of invasiveness. All pathologic findings were coded by S.T.H. retrospectively until 2009 and prospectively from January 2009 in close collaboration with G.B.P.

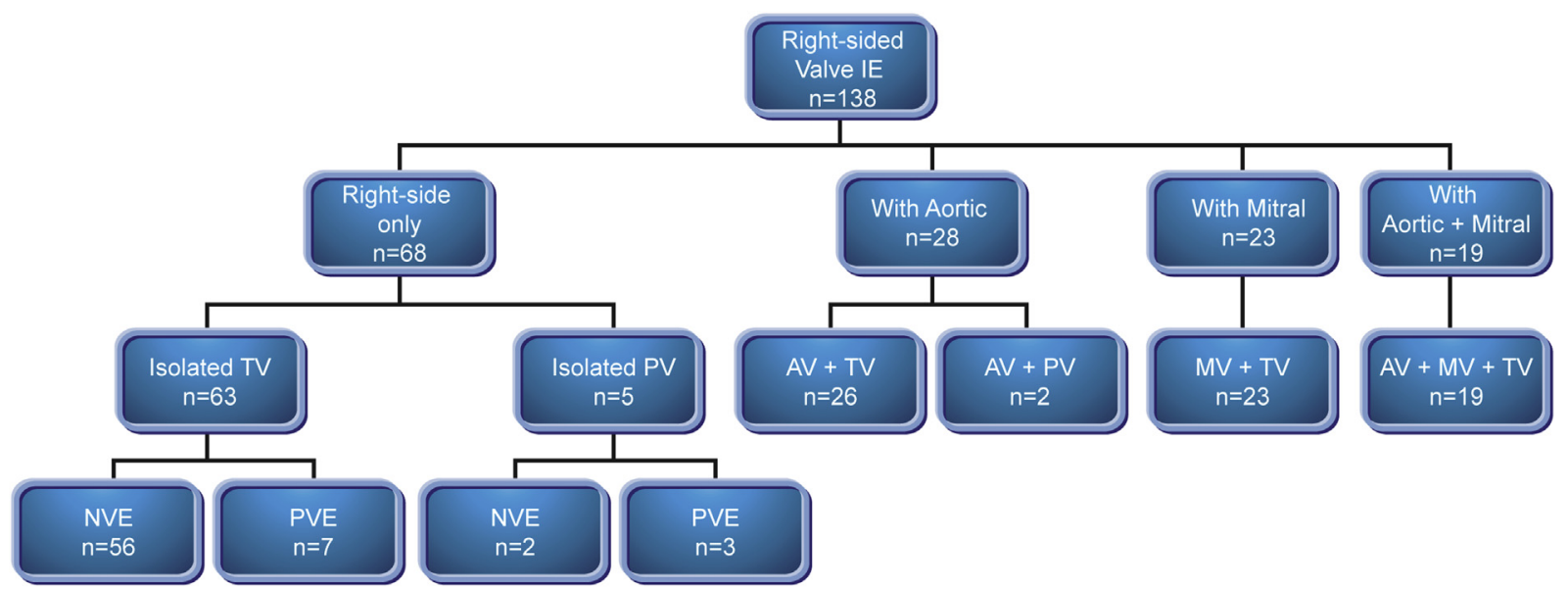

FIGURE 1. Right-sided IE by valve involvement. $I E$, Infective endocarditis; $T V$, tricuspid valve; $P V$, pulmonary valve; $A V$, aortic valve; $M V$, mitral valve; $N V E$, native valve endocarditis; $P V E$, prosthetic valve endocarditis. 


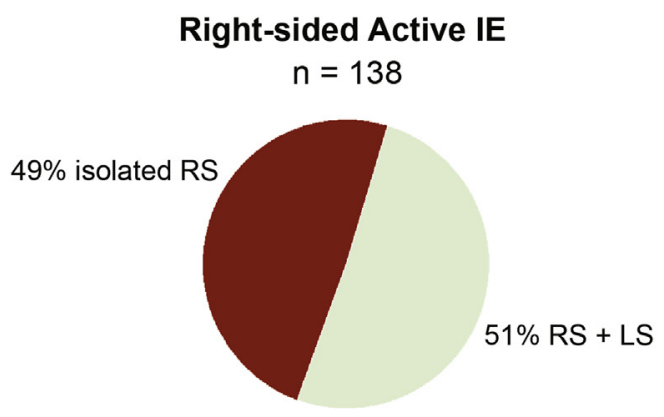

Isolated Tricuspid Valve

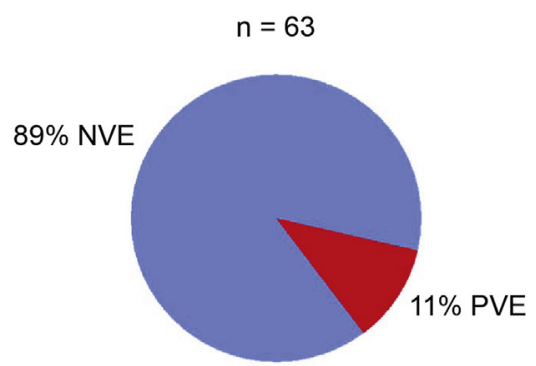

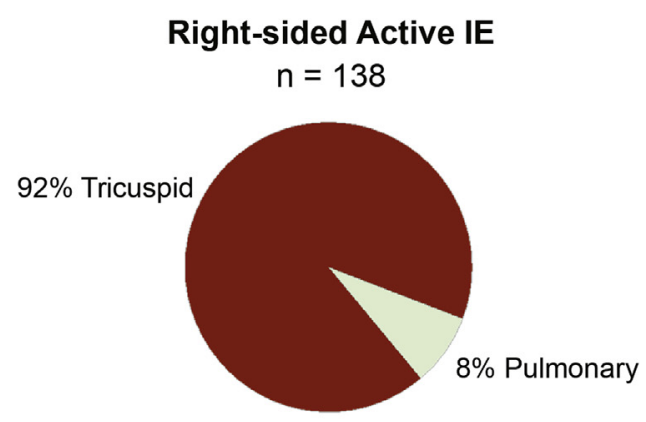

Isolated Pulmonary Valve

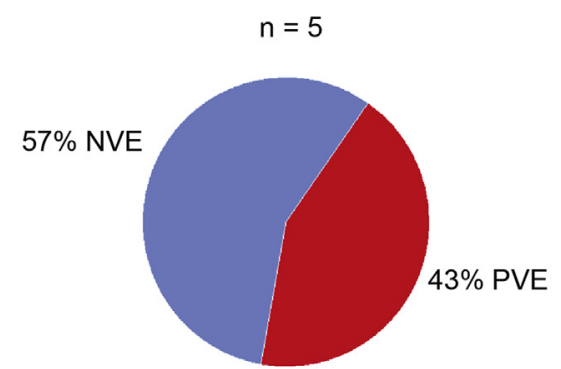

FIGURE 2. Distribution of right-sided active IE cases. $I E$, Infective endocarditis; $R S$, right-sided; $L S$, left-sided; $N V E$, native valve endocarditis; $P V E$, prosthetic valve endocarditis.

and occasionally the operating surgeon. For this study, a second experienced IE surgeon (J.L.N.), who was blinded to earlier results of invasion coding, reviewed all right-sided cases for invasiveness. He identified 4 cases for adjudicating possible invasive right-sided disease. Joint evaluation of intraoperative echocardiograms and operative notes revealed that 3 had combined right- and left-sided infection, with invasion originating from the left side. These were coded as noninvasive with respect to right-sided IE. The fourth case had vegetations under the septal leaflet of the tricuspid valve and on the right side of the membranous septum. The patient had developed heart block preoperatively with no explanation other than the infection; the rest of the tricuspid valve annulus was intact. By consensus, this case was coded as invasive right-sided IE.

\section{Data Analysis}

All analyses were performed with SAS statistical software (SAS version 9.2; SAS Institute, Cary, NC). Continuous variables are summarized by mean \pm standard deviation. Categorical variables are summarized by frequencies and percentages. Comparisons were made with the $\chi^{2}$ test or Fisher's exact test when frequency was less than 5 .

\section{RESULTS}

\section{Invasiveness of Right-Sided IE}

Only 1 case of right-sided IE was invasive, including those with concomitant left-sided IE $(0.72 \%$; 95 confidence interval $[\mathrm{CI}], 0.02 \%-4.0 \%$ ). This was true even when the organism was Staphylococcus aureus (Tables 2 and 3, Figure E1) or the patient had PVE (Figure 4). All other right-sided infections were limited to valve cusps or leaflets or were superficial, meaning that vegetations were nonpenetrating and could be peeled off the endocardium, with annulus integrity preserved.

\section{Invasiveness of Left-Sided IE}

In contrast to right-sided IE, of the 1224 patients with active left-sided IE, it was invasive in 408 of 633 with aortic valve IE ( $65 \%), 113$ of 369 with mitral valve IE $(31 \%)$, and 148 of 222 with combined aortic and mitral valve IE (67\%). Invasion was more common and deeper in aortic than in mitral valve IE patients (Figure 4, $A$ and $B$ ), with abscesses in $81 \%$ of aortic valve IE versus $54 \%$ in mitral valve IE $(P<.0001)$, abscess cavities in $39 \%$ of aortic valve IE versus $22 \%$ in mitral valve IE $(P=.0004)$, pseudoaneurysms in $12 \%$ of aortic valve IE versus $2.7 \%$ in mitral valve IE $(P=.002)$, and full annular circumference involvement in $33 \%$ of aortic valve IE versus $7.5 \%$ in mitral valve IE $(P<.0001)$. Invasion was also more common in PVE, but again more so for aortic than mitral valve IE (Figure 4, $C)$ : in aortic valve PVE, invasive disease occurred in $82 \%$ of patients compared with $41 \%$ for NVE $(P<.0001)$; in mitral valve PVE, invasive disease occurred in $41 \%$ of patients compared with $27 \%$ for NVE $(P=.4)$.

\section{Invasiveness in Combined Right- and Left-Sided IE}

Among the 70 patients with combined right- and left-sided IE for whom we presume the infection occurred simultaneously on both sides of the heart, no invasion was found on the right side $(0 \%, 95 \% \mathrm{CI}, 0 \%-5.2 \%)$, whereas in $33(47 \%, 95 \%$ CI, 36\%-59\%), IE was invasive on the left side ( 15 of 28 [52\%] with aortic valve IE, 4 of 23 [17\%] with mitral valve IE, and 14 of 19 [74\%] with combined aortic and mitral valve IE). 
TABLE 1. Clinical characteristics of patients with right-sided IE treated surgically $(\mathrm{n}=\mathbf{1 3 8})$

\begin{tabular}{|c|c|}
\hline Characteristics & No. $(\%)$ or mean \pm SD \\
\hline \multicolumn{2}{|l|}{ Demographics } \\
\hline Age, y & $49 \pm 16$ \\
\hline Female & $59(43)$ \\
\hline Body mass index, $\mathrm{kg} / \mathrm{m}^{2}$ & $27 \pm 6.9$ \\
\hline \multicolumn{2}{|l|}{ Presentation } \\
\hline NYHA functional class III-IV & $47(38)$ \\
\hline Emergency & $7(5.1)$ \\
\hline Previous stroke & $23(17)$ \\
\hline Previous myocardial infarction & $26(19)$ \\
\hline $\begin{array}{l}\text { Acute or chronic renal disease requiring } \\
\text { dialysis }\end{array}$ & $19(14)$ \\
\hline \multicolumn{2}{|l|}{ Cardiac comorbidity } \\
\hline Previous infective endocarditis & $19(14)$ \\
\hline \multicolumn{2}{|l|}{ Previous cardiac operation } \\
\hline 0 & $80(58)$ \\
\hline 1 & $39(28)$ \\
\hline 2 & $16(12)$ \\
\hline$\geq 3$ & $3(2.1)$ \\
\hline \multicolumn{2}{|l|}{ Aortic valve } \\
\hline Stenosis & $6(4.3)$ \\
\hline Severe regurgitation & $23(17)$ \\
\hline \multicolumn{2}{|l|}{ Mitral valve } \\
\hline Stenosis & $6(4.3)$ \\
\hline Severe regurgitation & $25(18)$ \\
\hline \multicolumn{2}{|l|}{ Tricuspid valve } \\
\hline Stenosis & $8(5.8)$ \\
\hline Severe regurgitation & $71(51)$ \\
\hline \multicolumn{2}{|l|}{ Pulmonary valve } \\
\hline Stenosis & $2(1.4)$ \\
\hline Severe regurgitation & $6(4.3)$ \\
\hline \multicolumn{2}{|l|}{ Prosthetic valve endocarditis } \\
\hline Any valve & $37(27)$ \\
\hline Aortic valve & $19(14)$ \\
\hline Mitral valve & $8(5.8)$ \\
\hline Tricuspid valve & $12(8.7)$ \\
\hline Pulmonary valve & $4(2.9)$ \\
\hline \multicolumn{2}{|l|}{ Valve affected } \\
\hline Aortic & $47(34)$ \\
\hline Normal tricuspid & 24 \\
\hline Bicuspid & 3 \\
\hline Prosthetic (mechanical/bioprosthetic) & 17 \\
\hline Allograft & 2 \\
\hline Autograft (previous Ross) & 1 \\
\hline Mitral & $42(30)$ \\
\hline Normal valve & 33 \\
\hline Prosthetic & 8 \\
\hline Prolapse & 1 \\
\hline Tricuspid & $131(95)$ \\
\hline Pulmonary & $7(5.1)$ \\
\hline Right-sided IE only & $68(49)$ \\
\hline \multicolumn{2}{|l|}{ Noncardiac comorbidity } \\
\hline Hypertension & $80(58)$ \\
\hline Pharmacologically treated diabetes & $31(23)$ \\
\hline
\end{tabular}

(Continued)
TABLE 1. Continued

\begin{tabular}{lc}
\hline \multicolumn{1}{c}{ Characteristics } & No. $(\%)$ or mean \pm SD \\
\hline Chronic obstructive pulmonary disease & $33(24)$ \\
Peripheral arterial disease & $23(17)$ \\
\hline
\end{tabular}

$S D$, Standard deviation; NYHA, New York Heart Association; IE, infective endocarditis.

\section{Nonsurgically Managed Right-Sided IE}

One of the 51 patients with right-sided IE managed nonsurgically had possible right-sided invasive disease $(2.0 \% ; 95 \%$ CI, $0.35 \%-10 \%)$. This patient had large vegetations beneath the septal leaflet of the tricuspid valve and a ventricular septal defect with a left-to-right shunt both to the right ventricle and atrium, with tricuspid valve regurgitation. It is uncertain whether this was right-sided invasive IE affecting the tricuspid valve, with disruption of the atrioventricular membranous septum, or ventricular septal defect endocarditis. Nine of the 18 patients $(50 \%$; $95 \%$ CI, 29\%-71\%) with combined right- and left-sided IE had left-sided invasive disease (definite in 5, likely in 4). In 22 of the 33 with isolated right-sided valve involvement, including the one with possible invasive disease, IE was caused by $S$ aureus, as it was in 8 of the 18 with both right- and left-sided valve involvement.

\section{DISCUSSION \\ Principal Findings}

The clinical observation that right-sided IE is rarely invasive was confirmed in a large group of surgically treated patients, with invasion observed almost exclusively on the left side of the heart. Both the surgical case of invasive right-sided IE and the nonsurgically managed patient that might be invasive had vegetations beneath the septal leaflet of the tricuspid valve and in the membranous septum. This is a protected area in which it is plausible that bacteria elaborating enzymes destructive of fibrous tissue may produce invasive disease.

Development of cavities, whether referred to as "abscesses," cavities, or pseudoaneurysms, requires high pressure and almost never occurs in the low-pressure right-side. (True abscesses still filled with pus are not displayed as cavities by echocardiography.)

We have observed numerous cases of aortic valve IE in which it has been obvious to us that the infection was primarily left-sided, with the invasion originating from the left side in different stages - early with septum bulging but with intact endocardium on the right aspect, with later breakthrough, and fistula and vegetations on the right side of the atrial septum through the perforation. Most often, invasion toward the right side takes place behind and on the right aspect of the central fibrous body, with the destruction progressing toward the conduction bundle and the atrioventricular node and continuing to the atrioventricular portion of the membranous septum and the commissure between the 
Left-sided Active IE

$n=1224$

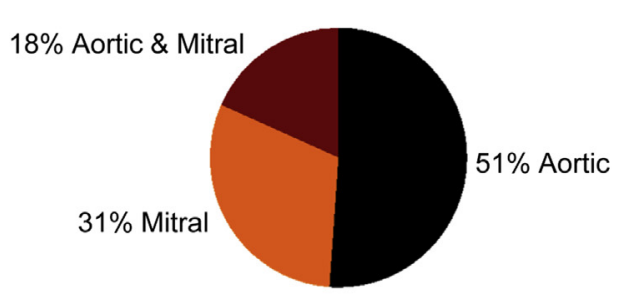

Mitral Valve

$n=369$

8\% Previous Repair

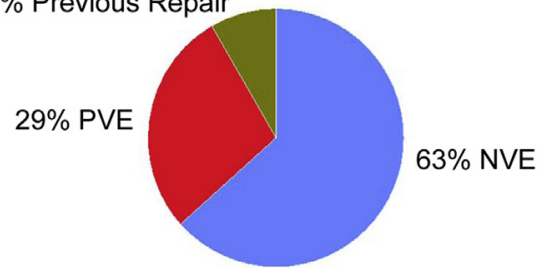

Aortic Valve

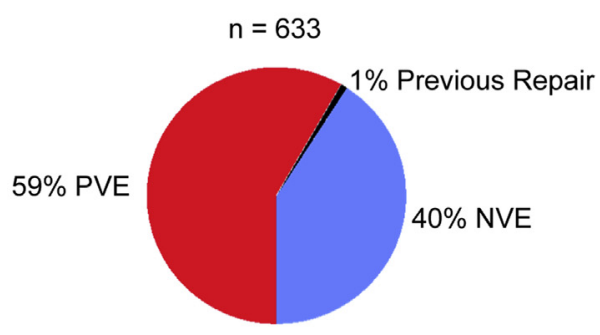

Aortic + Mitral Valve

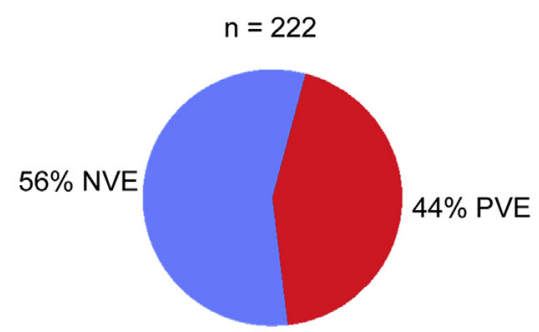

FIGURE 3. Distribution of left-sided active IE cases. $I E$, Infective endocarditis; $P V E$, prosthetic valve endocarditis; $N V E$, native valve endocarditis.

septal and anterior leaflets of the tricuspid valve. This is the primary mechanism for development of heart block. ${ }^{12} \mathrm{~A}$ good demonstration of this is a recent case we had of aortic PVE with right-sided invasion and conduction anomaly. At initial echocardiography, the patient had no communication to the right atrium (Videos 1 and 2) but a week later had a large aorta-to-right-atrium fistula (Videos 3 and 4).

$S$ aureus was the predominant organism for both rightand left-sided IE, and even more so on the right side. In addition, in left-sided IE, mitral valve invasive disease was less common than aortic valve invasive disease. All these differences are clinically important because they determine progression and development of complications and inform clinical management.

\section{Differences Between Right- and Left-Sided IE}

Right- and left-sided IE are 2 distinct entities clinically. Right-sided IE is more benign than left-sided IE, despite the greater prevalence of $S$ aureus. Of patients with right-sided IE, only $5 \%$ to $16 \%$ do not respond to medical therapy and eventually require surgical intervention (Video 5), in contrast to medical failure of $40 \%$ to $50 \%$ for left-sided IE. ${ }^{1-4,8,9,13}$ The more benign course of right-sided IE also is seen in non-staphylococcal infections. For example, Reyes and colleagues ${ }^{14}$ noted in a series of injection drug users with pseudomonas endocarditis that $31 \%$ with isolated right-sided involvement responded to medical therapy alone, but only $14 \%$ with left-sided involvement did. Today, in the era of increasing intravenous

TABLE 2. Microbiologic etiology of right-sided IE

\begin{tabular}{|c|c|c|c|c|}
\hline \multirow[b]{2}{*}{ Microorganism* } & \multicolumn{3}{|c|}{ Isolated right-sided IE $(\mathrm{n}=68)$} & \multirow[b]{2}{*}{$\begin{array}{c}\text { Right- and } \\
\text { left-sided }(n=70)\end{array}$} \\
\hline & $\begin{array}{c}\text { Tricuspid } \\
\text { valve }(n=63)\end{array}$ & $\begin{array}{c}\text { Pulmonary } \\
\text { valve }(n=5)\end{array}$ & $\begin{array}{c}\text { Overall isolated } \\
\text { right-sided }(n=68)\end{array}$ & \\
\hline Staphylococcus aureus & $27(43)$ & $0(0)$ & $27(40)$ & $31(44)$ \\
\hline Coagulase-negative staphylococcus & $16(25)$ & $2(40)$ & $18(26)$ & $14(20)$ \\
\hline Enterococcus & $2(3.1)$ & $1(20)$ & $3(4.4)$ & $6(8.6)$ \\
\hline Viridans group streptococcus & $2(3.1)$ & $0(0)$ & $2(2.9)$ & $6(8.6)$ \\
\hline Gram-positive cocci $\dagger$ & $0(0)$ & $0(0)$ & $0(0)$ & $4(5.7)$ \\
\hline Fungus & $4(6.3)$ & $0(0)$ & $4(5.9)$ & $0(0)$ \\
\hline Polymicrobial & $3(4.7)$ & $1(20)$ & $4(5.9)$ & $0(0)$ \\
\hline Other & $3(4.7)$ & $1(20)$ & $4(5.9)$ & $6(8.6)$ \\
\hline Not identified & $6(9.5)$ & $0(0)$ & $6(8.8)$ & $3(4.3)$ \\
\hline
\end{tabular}

Data presented as n (\%). IE, Infective endocarditis. *Final diagnosis. †Not identified further. 
TABLE 3. Microbiologic etiology of left-sided IE

\begin{tabular}{|c|c|c|c|c|c|c|c|}
\hline \multirow[b]{2}{*}{ Microorganism* } & \multicolumn{2}{|c|}{ Invasive } & \multicolumn{2}{|c|}{ Noninvasive } & \multicolumn{3}{|c|}{ Overall left-sided } \\
\hline & $\begin{array}{c}\mathrm{AV} \\
(\mathrm{n}=\mathbf{4 0 8})\end{array}$ & $\begin{array}{c}\text { MV } \\
(\mathbf{n}=\mathbf{1 1 3})\end{array}$ & $\begin{array}{c}\mathbf{A V} \\
(\mathbf{n}=\mathbf{2 2 5})\end{array}$ & $\begin{array}{c}\text { MV } \\
(\mathbf{n}=\mathbf{2 5 6})\end{array}$ & $\begin{array}{c}\mathbf{A V} \\
(\mathrm{n}=6 \mathbf{6 3 3})\end{array}$ & $\begin{array}{c}\text { MV } \\
(\mathbf{n}=369)\end{array}$ & $\begin{array}{c}\mathbf{A V}+\mathbf{M V} \\
(\mathbf{n}=\mathbf{2 2 2})\end{array}$ \\
\hline Staphylococcus aureus & $90(22)$ & $37(33)$ & $31(14)$ & $72(28)$ & $121(19)$ & $109(30)$ & $53(24)$ \\
\hline Coagulase-negative staphylococcus & $86(21)$ & $16(14)$ & $30(13)$ & $29(11)$ & $116(18)$ & $45(12)$ & $41(18)$ \\
\hline Enterococcus & $54(13)$ & $6(5.3)$ & $43(19)$ & $30(12)$ & $97(15)$ & $36(9.7)$ & $31(14)$ \\
\hline Viridans group streptococcus & $50(12)$ & $12(11)$ & $45(20)$ & $58(23)$ & $95(15)$ & $70(19)$ & $42(19)$ \\
\hline Gram-positive cocci $\dagger$ & $17(4.1)$ & $12(11)$ & $12(5.3)$ & $18(7.0)$ & $29(4.5)$ & $30(8.1)$ & $17(7.7)$ \\
\hline Fungus & $14(3.4)$ & $1(0.88)$ & $7(3.1)$ & $6(2.3)$ & $21(3.3)$ & $7(1.8)$ & $4(1.8)$ \\
\hline Polymicrobial & $10(2.4)$ & $5(4.4)$ & $8(3.5)$ & $11(4.3)$ & $18(2.8)$ & $16(4.3)$ & $3(1.4)$ \\
\hline Other & $53(13)$ & $10(8.8)$ & $27(12)$ & $11(4.3)$ & $80(13)$ & $21(5.6)$ & $20(9.0)$ \\
\hline Not identified & $32(7.8)$ & $14(12)$ & $20(8.9)$ & $19(7.4)$ & $52(8.2)$ & $33(8.9)$ & $11(5.0)$ \\
\hline
\end{tabular}

Data presented as n (\%). $A V$, Aortic valve; $M V$, mitral valve. *Final diagnosis. $†$ Not identified further.
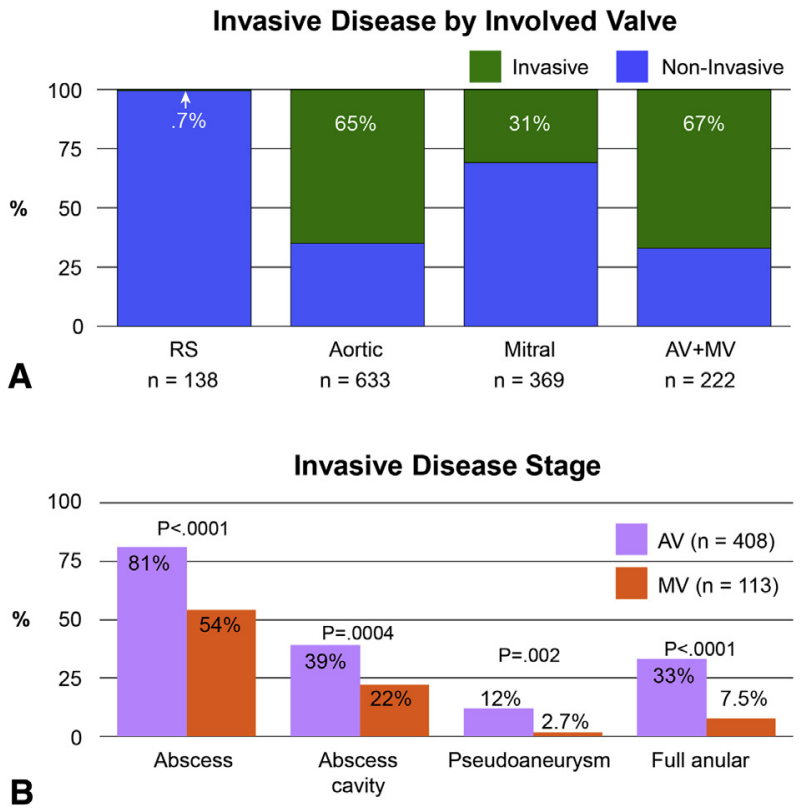

Invasive Disease: Native vs. Prosthetic Valve

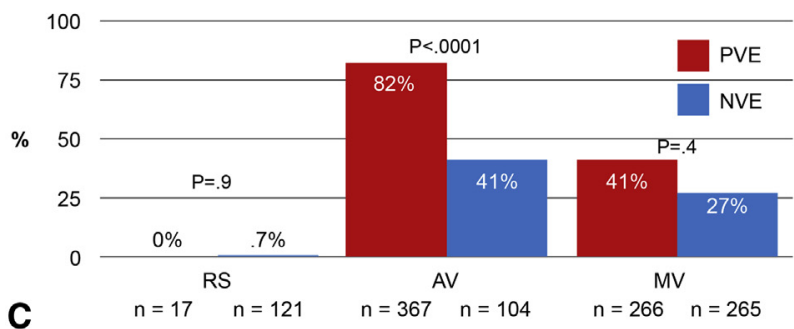

FIGURE 4. Invasive disease distribution. A, By involved valve. Rightsided IE was rarely invasive, and aortic valve IE was more invasive than mitral valve IE. B, By invasive disease stage. Invasion was greater in both type and degree in aortic than mitral valve IE. C, By native versus prosthetic valve IE. Invasive disease on the left side was more common in prosthetic valve IE, but more so for aortic than mitral valve IE. $R S$, Right-sided; $A V$, aortic valve; $M V$, mitral valve; $P V E$, prosthetic valve endocarditis; $N V E$, native valve endocarditis. drug abuse, large tricuspid valve vegetations, continued bacteremia, and septic pulmonary embolism are equally important indications for surgery in patients with right-sided IE as is severe tricuspid valve regurgitation. ${ }^{1,13}$

\section{Why Are Right-Sided and Left-Sided IE Different?}

Our observations support the suggestion that invasion and development of cavities and "abscesses" are at least in part driven by pressure rather than by organism. In this context, the lesser invasiveness of mitral valve IE compared with aortic valve IE may be explained by the finding that most invasion sites along the mitral annulus are open and decompressed toward the left atrium (Videos 6 and 7).

Other possible explanations for differences in invasiveness between right- and left-sided IE have been suggested. Oxygenated blood on the left side may be a contributing factor, because causative organisms are predominantly aerobic.

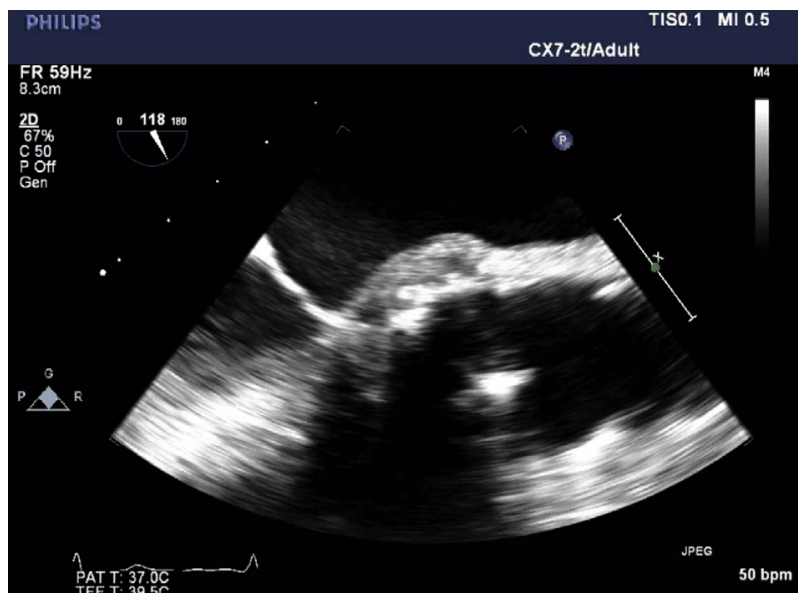

VIDEO 1. Aortic prosthetic valve endocarditis with aortic root abscess (prefistula stage). Video available at: http://www.jtcvsonline.org/article/ S0022-5223(17)31722-1/fulltext. 


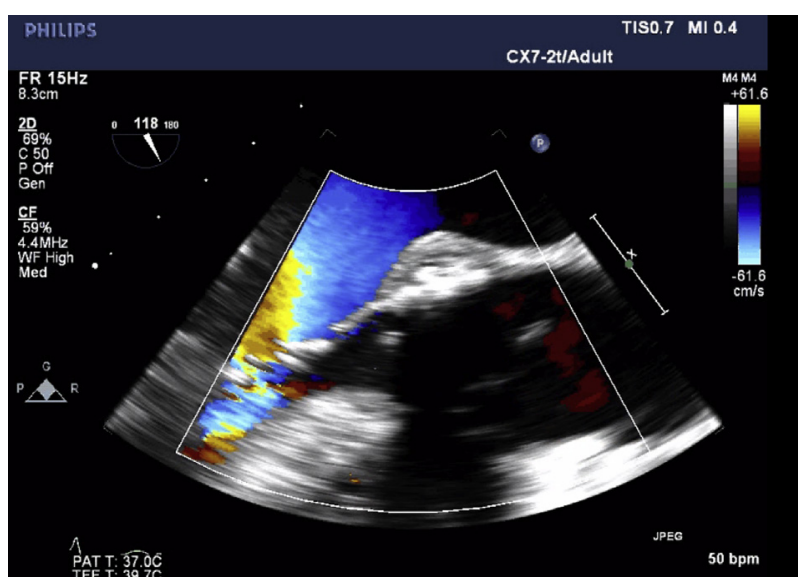

VIDEO 2. Aortic prosthetic valve endocarditis with aortic root abscess (prefistula stage). Color added to the echocardiogram clip from Video 1. Video available at: http://www.jtcvsonline.org/article/S0022-5223(17) 31722-1/fulltext.

Freedman and colleagues ${ }^{6}$ hypothesized that there is something different in host-microbial interactions on the right versus left sides of the heart. In their experimental studies using $S$ aureus, Candida albicans, and Escherichia coli, the number of organisms found in the vegetations of left-sided IE were several orders of magnitude higher than in the vegetations of right-sided IE. ${ }^{6}$ The reason for this remains unclear, but it may reflect less flow- and pressure-related shear stress that encourages greater vegetation bulk on the right side (Central Figure). Microorganisms also may differ in their interactions with endothelium on the right and left sides of the heart. Levine and colleagues ${ }^{15}$ observed that streptococci infected left-sided valves more readily than right-sided valves and proposed that intrinsic differences in the endothelium of right- and left-sided heart valves cause certain organisms to adhere to specific valves.

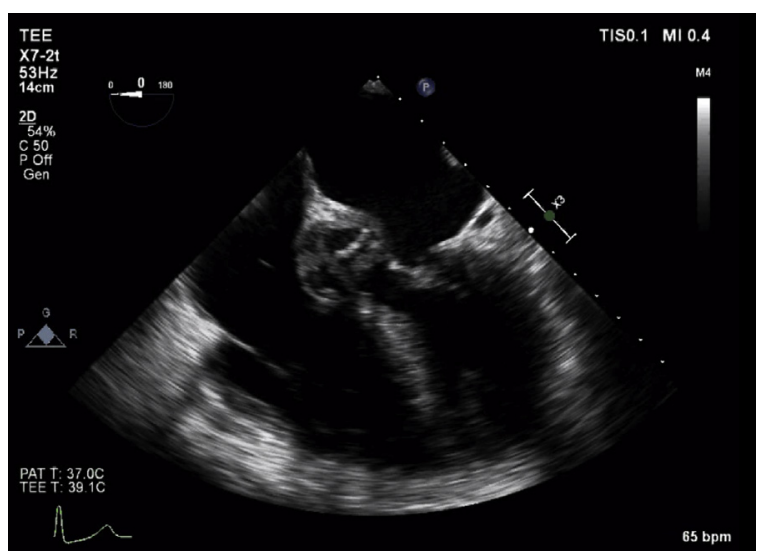

VIDEO 3. Echocardiogram 1 week later from the patient in Videos 1 and 2. There is now an aorto-right atrial communication (postfistula formation). Video available at: http://www.jtcvsonline.org/article/S00225223(17)31722-1/fulltext.

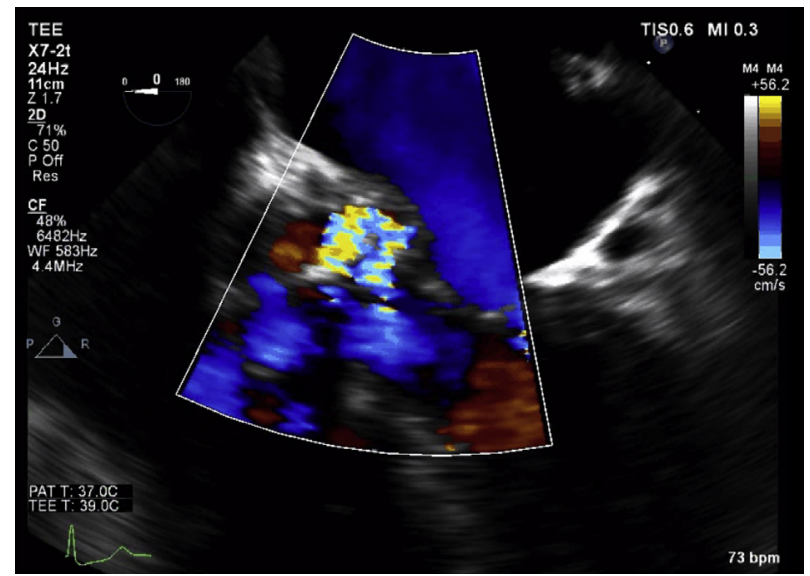

VIDEO 4. Echocardiogram 1 week later from the patient in Videos 1 and 2. There is now an aorto-right atrial communication (postfistula formation). Color added to echocardiogram clip from Video 3. Video available at: http://www.jtcvsonline.org/article/S0022-5223(17)31722-1/fulltext.

Rarity of invasion in right-sided IE also may be explained by qualitative and quantitative differences in microbial growth and production of toxins and enzymes on the left and right sides of the heart. ${ }^{3,6}$ Invasiveness also may be related to the propensity of infection to involve the free margin of the valve more often than the annulus on the right side, due to its pure muscular, rather than fibromuscular, nature, as on the left side. ${ }^{4}$ In addition, local factors, such as differences in the blood supply to the annulus and surrounding myocardium, may account for different manifestations of IE among the mitral, aortic, and tricuspid valves. ${ }^{3,4}$

\section{Limitations}

Although our series of right-sided IE is large, this is a single-institution study. Some cases of right-sided IE are managed medically, and for these patients, we were able to assess invasiveness only by noninvasive imaging studies without operative observations. Our belief that right-sided IE is rarely invasive is not contradicted by any previous reports, and both clinical hypotheses and experimental

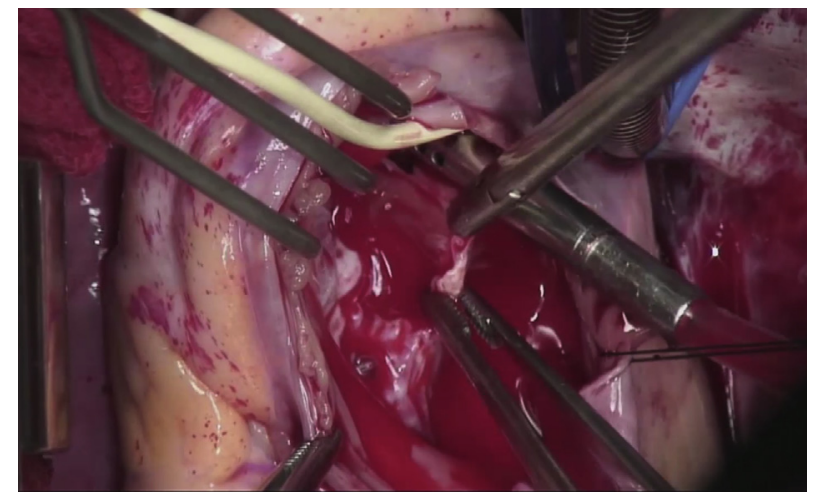

VIDEO 5. Debridement and repair in a case of tricuspid valve endocarditis. Video available at: http://www.jtcvsonline.org/article/ S0022-5223(17)31722-1/fulltext. 


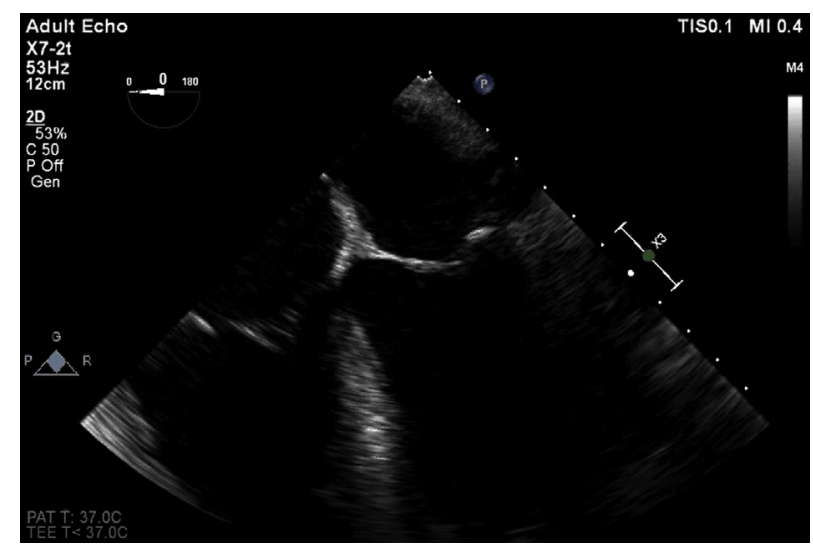

VIDEO 6. Invasive mitral valve endocarditis, with severe mitral regurgitation due to perforation near base of the posterior mitral valve leaflet. It is in direct communication with pseudoaneurysm cavity adjacent to mitral annulus laterally. Video available at: http://www.jtcvsonline.org/ article/S0022-5223(17)31722-1/fulltext.

studies provide plausible mechanisms. Along with organism and virulence, another variable that could be important in deciding the pathology stage and invasion is duration of the disease, which is difficult to extract retrospectively. This study includes 70 patients with involvement of both right- and left-sided valves in whom all factors, including duration of illness, are presumably identical for both the right and left sides. Even in this group, the marked difference in invasiveness between the right and left sides is prominent.

\section{CONCLUSIONS}

Right-sided IE is rarely invasive, aortic valve IE is most invasive, and mitral valve IE is in between. The explanation for these differences may be in part differences in host-microbial interactions on the right and left sides of the heart. However, a logical explanation is that these

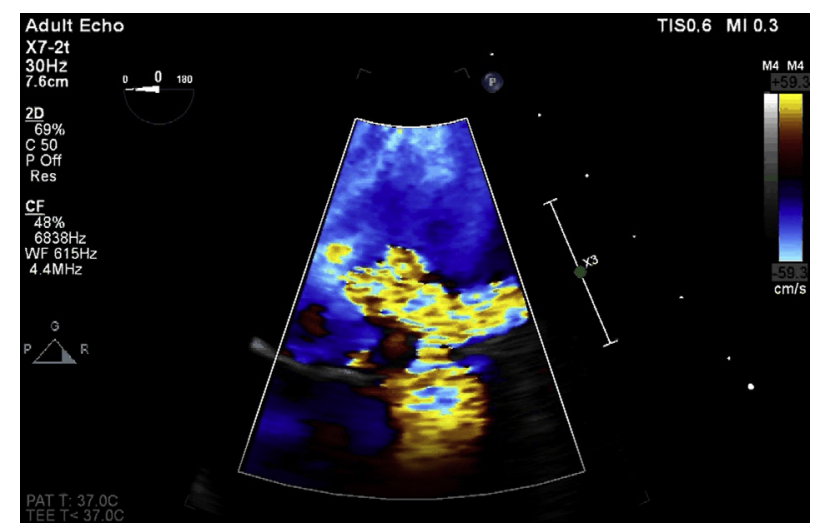

VIDEO 7. Invasive mitral valve endocarditis, with severe mitral regurgitation due to perforation near base of the posterior mitral valve leaflet. It is in direct communication with pseudoaneurysm cavity adjacent to mitral annulus laterally. Color added to echocardiogram from Video 6. Video available at: http://www.jtcvsonline.org/article/S0022-5223(17)31722-1/fulltext. differences reflect a driving force of pressure that is lower on the right side. Lesser invasiveness of mitral compared with aortic valve IE would then be logical because mitral valve invasion sites are most often open to, and decompressed to, the left atrium. Understanding invasiveness is important to understanding the pathogenesis, progression, complications, and prognosis of IE. Depending on the infected valve, differences in invasiveness predict clinical development and inform management. Depressurizing the infected area is part of what an effective operation for IE accomplishes.

\section{Conflict of Interest Statement}

Authors have nothing to disclose with regard to commercial support.

\section{References}

1. Habib G, Lancellotti P, Antunes MJ, Bongiorni MG, Casalta JP, Del Zotti F, et al 2015 ESC Guidelines for the management of infective endocarditis: The Task Force for the Management of Infective Endocarditis of the European Society of Cardiology (ESC). Endorsed by: European Association for Cardio-Thoracic Surgery (EACTS), the European Association of Nuclear Medicine (EANM) Eur Heart J. 2015;36:3075-128.

2. Murdoch DR, Corey GR, Hoen B, Miro JM, Fowler VG Jr, Bayer AS, et al. Clinical presentation, etiology, and outcome of infective endocarditis in the 21st century: the International Collaboration on Endocarditis-Prospective Cohort Study. Arch Intern Med. 2009;169:463-73.

3. Akinosoglou K, Apostolakis E, Koutsogiannis N, Leivaditis V, Gogos CA. Rightsided infective endocarditis: surgical management. Eur J Cardiothorac Surg. 2012;42:470-9.

4. Carozza A, De Santo LS, Romano G, Della Corte A, Ursomando F, Scardone M, et al. Infective endocarditis in intravenous drug abusers: patterns of presentation and long-term outcomes of surgical treatment. J Heart Valve Dis. 2006;15:125-31.

5. Robbins MJ, Soeiro R, Frishman WH, Strom JA. Right-sided valvular endocarditis: etiology, diagnosis, and an approach to therapy. Am Heart J. 1986;111:128-35.

6. Freedman LR, Arnold S, Valone J. Experimental endocarditis. Ann N Y Acad Sci. 1974;236:456-65.

7. Frontera JA, Gradon JD. Right-side endocarditis in injection drug users: review of proposed mechanisms of pathogenesis. Clin Infect Dis. 2000;30:374-9.

8. Musci M, Siniawski H, Pasic M, Grauhan O, Weng Y, Meyer R, et al. Surgical treatment of right-sided active infective endocarditis with or without involvement of the left heart: 20-year single center experience. Eur J Cardiothorac Surg. 2007;32: 118-25.

9. Gaca JG, Sheng S, Daneshmand M, Rankin JS, Williams ML, O'Brien SM, et al. Current outcomes for tricuspid valve infective endocarditis surgery in North America. Ann Thorac Surg. 2013;96:1374-81.

10. Hussain ST, Shrestha NK, Gordon SM, Houghtaling PL, Blackstone EH, Pettersson GB. Residual patient, anatomic, and surgical obstacles in treating active left-sided infective endocarditis. J Thorac Cardiovasc Surg. 2014;148:981-8.e4.

11. Li JS, Sexton DJ, Mick N, Nettles R, Fowler VG Jr, Ryan T, et al. Proposed modifications to the Duke criteria for the diagnosis of infective endocarditis. Clin Infect Dis. 2000;30:633-8.

12. Pettersson GB, Hussain ST, Shrestha NK, Gordon S, Fraser TG, Ibrahim KS, et al Infective endocarditis: an atlas of disease progression for describing, staging, coding, and understanding the pathology. J Thorac Cardiovasc Surg. 2014;147:1142-9.e2.

13. Baddour LM, Wilson WR, Bayer AS, Fowler VG Jr, Tleyjeh IM, Rybak MJ, et al Infective endocarditis in adults: diagnosis, antimicrobial therapy, and management of complications: a scientific statement for healthcare professionals from the American Heart Association. Circulation. 2015;132:1435-86.

14. Reyes MP, Palutke WA, Wylin RF. Pseudomonas endocarditis in the Detroit Medical Center. 1969-1972. Medicine (Baltimore). 1973;52:173-94.

15. Levine DP, Crane LR, Zervos MJ. Bacteremia in narcotic addicts at the Detroit Medical Center. II. Infectious endocarditis: a prospective comparative study Rev Infect Dis. 1986;8:374-96.

Key Words: endocarditis, right sided, invasiveness, chamber pressure 
Prevalence of Staphylococcus aureus IE

100

75

$\% \quad 50$

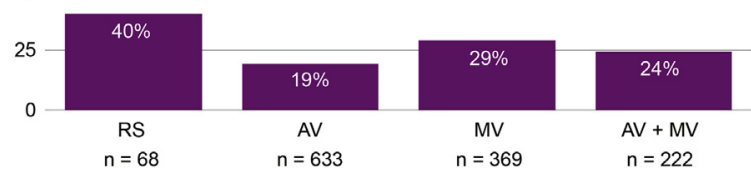

FIGURE E1. Prevalence of Staphylococcus aureus IE by involved valve.

$I E$, Infective endocarditis; $R S$, right-sided; $A V$, aortic valve; $M V$, mitral valve. 